\title{
The Role of Mainstream Schools in Turkish Speaking Children's Achievement in the UK
}

\author{
Ahmet Kose \\ Faculty of Psychology and Educational Sciences, University Of Bucharest \\ Romania \\ Email: akose73@gmail.com
}

\begin{abstract}
This study takes into account the language-related immigration issues of Turkish Speaking folks. Therefore, it studies TSSs as bilingual learners and English as additional language learners in terms of arrivals to the mainstream school, in the UK context. Ethnic and identity issues are also intrigued in the construction of TS Communities in the UK. In addition, in this work I examine the history of Turkish Speaking Communities' immigration to the $U K$ and provide data conducting first and secondary sources.

In this study, I provide a literature review on identity issues, settlement patterns of Turkish-Speaking People and their immigration history. I also present existing literature on bilingual education, supplementary schools and after-school clubs.
\end{abstract}

Kewwords--- immigration issues; bilingual learners; Turkish Speaking Communities; Ethnic and identity issues

\section{IDENTITY ISSUES}

Many scholars have showed interests in the area of identity issues. They have presented different viewpoints and interpretations on identity and its outcomes. As it is known that ones identities are our differences in various forms such as ethnicity, race, gender, class, color, place of origin. On the other hand, differences occur in terms of access to power and recourses. Likewise, Turkish identities can be formed on differences of ethnicity, religion, culture and region. However, Cummins (1996:13) defines the identities as "the way in which identities are negotiated in the classroom are strongly influenced by the assumptions in regard to culture and language in the wider society".

It could be said that Turks themselves come from different backgrounds. The terms "Turk" and "Turkish" may represent the dwellers' country of origin rather than racial and ethnic affiliations. Therefore, people from Turkey can be identified as Turkish, may be Kurdish, Cypriot Turkish, Cypriot Cypriot.

The Turkish identities, which are being shaped inevitably, challenge relations of normality and marginality, inclusion or exclusion. When Turkish immigrants come to the Britain, they enter into a culture where the English are powerful, and the former have to deal with the boundaries of differences. Turks may not be easily accepted as "British" due to their ethnic and religious backgrounds. In the British context, Turkish immigrants' differences may make more difference than white European immigrants'. Decades ago as in the example; some of white Europeans had experienced similar patterns such as Irish, Italians and Jews (Bonnett, 2000; Ignatiev, 1996), today Muslim immigrants in the United Kingdom face the same dilemma of being Turkish and Muslim can often result in difficulties for adopting and adapting British culture and disadvantages for access to power and resources. To some extent, identity can be mapped as we set our boundaries in between 'who we are and who we are not, who we want to be and who we do not want to be and act upon on those decisions'(LCSS, 2009).

According to Cummins (1996: 4) "when educators and culturally diverse parents become genuine partners in children's education, this partnership repudiates the myth that culturally diverse parents are apathetic and do not care about their children's education". On the other hand, he also points out that (1996:4) "if teachers are not learning much from their students, it is probably that their students are not learning much from them".

\section{IMMIGRATION HISTORY}

The history of Turkish speaking (TS) communities has been recorded and researched by a few scholars such as Mehmet Ali (2001), Issa (2005), Kucukcan (2001), Dedezade (2001). TS communities in the UK consist of Turkish Cypriots, mainland Turks and Kurdish communities. Turkish Cypriots started to come to the United Kingdom after 1950s (Kucukcan, 2001). They were the earliest settlers who were the pioneer immigrants from Turkey and Cyprus coming to the UK. They were followed by mainland Turks in the early 1970s (Mehmet Ali, 2001). These two groups were joined by Turkish-speaking Kurdish families later in the 1980s. At present, it is estimated that the TS people in the UK are around three hundred thousand (Issa, 2005). Although, there is given numbers, it is not possible to verify the estimates 
precisely because the census data appears to have failed to measure TS population accurately in Britain. The TS population has been identified in various numbers, in between 65,000 to 300,000 (Issa, 2005).

It can be said that the UK was one of the first few countries to open its doors to a large number of immigrant workers. They were especially coming from the Commonwealth. In this aspect, Turkey was not a main source for the work force. Therefore, there were no special arrangements between Britain and Turkey to provide workers. However, there were a number of western European countries such as Germany that made arrangements regarding with Turkish immigrant workers. While many of the TS immigrants went to Germany, France, Belgium and Netherlands, the UK was receiving immigrants from other countries in the late 1950s and 1960s. Therefore, it can be assumed that a large number of Turk workers migrated to these countries during the above-mentioned decade.

\section{THE TURKISH CYPRIOTS:}

It is clearly known that the Turkish Cypriots are the first ethnic group who migrated to Britain among other Turkish speaking communities. Of course, there are Turkish Cypriots and Greek Cypriots that started to settle in Britain at about the same dates coming from the island and once and where they used to share the land. Immigration patterns in between Turkish Cypriots and Greek Cypriots are alike after it is therefore; I have discussed their settlements too under the very title of Cypriots.

The immigration history of these two clans could be traced a little further back to the colonization process of British Empire in 1914. After being a subject of the Crown immigration from Cyprus to Britain had started in the early 1920 s and almost 1000 immigrants appeared in the UK by 1930s (Oakley, 1979) It can be said that there are several reasons of migration of Turkish Cypriots. One of the main reasons could be counted as economical (Sonyel, 1988) which fueled immigration process by 1958, the number of only Turkish Cypriots had increased to 8,500 (Bhatti, 1981). Other reasons of emigrating from Cyprus to Britain are as follows; joining the commonwealth, increasing economical statues (being poor), political and unfinished problems related to the politics (Bhatti, 1981). The number of people has also continued to increase rapidly once Cypriots's shops began to appear in the media (Kucukcan, 1999).

Cyprus joined the Commonwealth after its independence and important number of people arrived to the UK. The number of immigrants had reached 78,846 by 1962s after the Cypriots were allowed to come to the UK while there were agitation and problems in the island (Kucukcan, 2001). Costantinides (1977) and George (1960) also stated that the main portion of migration had taken place in between 1878 and 1960 during the period of British rule. However, migration process can be examined in three different stages (Alkan and Constantinides, 1982). Pre World war migration; Constantinides (1977) showed that the migrants were either seamen, merchants, single men and students who arrived to seek a better life conditions in Britain. The following stage can be identified as post war migration (1945 - 1974); the major migration is said to have taken place in this era. And the final stage is after the 1974 war migration process; there was a refugee migration process after the war broke out between the two communities. According to the Swann's report (1985) and Clough and Quarmby (1978) following the war, around 11,000 refugees immigrated to the UK. After the war in 1974, a number of thousands of people left Cyprus for the Britain (Oakley, 1979) and their number reached 160,000 in the early 1980s and almost one fourth of them were thought to be Turkish Cypriot (King, 1982).

\section{MAINLAND TURKS}

The people who used to live in the mainland established links with the existing Cypriot Turks already living in the UK. The existence of Cypriot Turks gave mainland Turks great opportunities to follow them, further to be employed by them where Cypriot Turks had already opened shops, etc in 1960s and 1970s (Kucukcan, 2001). The history of mainland Turks' migration goes back to the 1950s (Issa, 1987). In 1950s, there were a great number of people who had reached Europe to find a better life conditions especially, Germany was the leading country where most of the mainland Turks immigrated. During those years, Britain had also attracted thousands of people from the mainland of Turks. Germany's fast growing industry needed workforce and mainland Turks brought manpower to the country. However, there is not much information about the immigration patterns of the mainland Turks coming to Britain. It is known that only in 1970s and 1980s legal workers had arrived to the Britain. Turkish immigrants were mainly working in the textile industry and the catering (Paine, 1974; Berger, 1975).

\section{TURKISH SPEAKING KURDS}

One of the ethnic groups in the Turkish speaking community in the UK is Kurds from Turkey. There are other Kurds coming from Iran and Iraq. It is obvious that the Kurdish migration began due to various reasons such as political and economical. According to Dick (2004) the first arrival of Kurdish refugees took place in 1958 with a small number of people. They were from both Turkey and Iraq. Three migration phases have been recorded. The first one is known to be between 1987 to 1988. The second phase is between May 1989 and till the visa regulations had amended on 23rd 1989. 
After the imposition of visa demands and the superiority of the PKK associated organizations during the early part of the 1990s begins the third phase of the migration process of Turkish - Kurdish community who dwelled in the North London.

\section{SETTLEMENT PATTERNS IN LONDON}

TS Communities are not as big as other ethnic communities such as people from Ghana, Somali, Pakistan. Even though, they are small communities that can be seen all around the UK, for instance in Wales, Manchester, Edinburgh, but it is certain that the majority of the TSCs are dwelling around London. According to Kucukcan (1999:62) "Turks were not required to have visas till 1989, many of them came to Britain". The majority of the immigrant Turks were single not as families. They were either single men or left their wives and children behind to come to the UK. Following the chain immigration, they preferred to stick together. Ladbury (1979:309) also stated that "there was a willingness to stay here among the Turks". What Kucukcan (1999) believed was "the use of social network, kinship relations and patronage has perpetuated the concentration of the Turks in the same quarters of the city". Now the majority of Turks live in the Greater London. They also preferred to live with Turkish neighbors, which later constructed, Turkish 'mahallas'. Turkish speaking communities also diversify among themselves according to not only their ethnicity but also religion, ideology and culture. To a great extent, traditional homeland diversity as well as ethnicity, identity, culture, ideology, religion are rebuilt and reconstructed in the British context.

The Turkish Cypriot communities were settled in the areas of Angel, Islington, toke Newington and Camden. Now, they have moved to Haringey, Enfield and Lewisham and other London boroughs.

The mainland Turks' settlement could be observed in areas like Hackney, Wood Green, Edmonton, Stoke Newington, Newington Green, Tottenham, Barnet, Palmers Green, Ponders end, the city of Westminster, Barnet, Kensington and Chelsea, Haringey. Turkish Cypriots attracted mainland Turks with their earlier established businesses. Now, they have their own small businesses such as kebab shops, supermarkets, etc and houses in the outer boroughs of London.

Turkish - Kurdish speaking communities were inspired by Turkish Cypriots who used to run garment and catering trades to settle in the areas of hackney and Haringey in and after 1980s (Hackney Council, 1993).

\section{BILINGUAL EDUCATION}

Various interviews conducted by Mehmet Ali (2001), an international education consultant and an author who specialises in multiculturalism, bilingualism and equalities work with the TS communities, women, and young people, revealed that TS youth suffered stereotyping and racism at school and in some cases had to struggle against low expectations from teachers. In the UK schools, the young learners identified themselves as quiet and shy. This also caused them not to be visible in the school system. Cummins (1996:2) also stressed that "when students' language, culture and experience are ignored or excluded in classroom interactions, students are immediately starting from a disadvantage".

While settling in the UK, Turkish Speaking communities started to grow and their needs of social cohesion in the dominant society are becoming various. One of the main issues was the home language to interact with host people. Beside parents, the new coming children also faced certain difficulties with the language use. Children started to learn English at schools as additional Language. According to Cummins (2000) researches show that although there is a vast difference among pupils, for an average second language learner it takes five to ten years to grab the language academically. Therefore, where more than $50 \%$ of students are bilingual, different language development in the classroom at different levels need to be thought as a whole curriculum issue.

Rutter (1994:71) suggested "pupils with EAL need to experience the 'social learning' of English. It can be said that the most effective way of learning English within the classroom are their peers and the culturalisation context as the powerful sources for the EAL learners. Rutter (1994) and Cummins (1993) believe that bilingual learners are seen in this model to acquire English language skills most effectively by working alongside their English - Speaking peers, as they develop social relations with them. That is how immigrant children learn a new language to be motivated in relationship to how quickly they want or feel the need of English - Speaking and predominant community. The DfES (2006) (Department for Education and Skills) recommend various strategies to help teachers support students at numerous points of learning English and identify different factors that enable bilingual learners to develop their academic proficiency in English in the mainstream schools. However, Gibbons (1991, p.119) and Franson (2001, p.114) stated that 'it must be stressed that although the specific principals suggested are particularly relevant to the needs of bilingual learners, many are also relevant to the learning of all children'.

The students, who arrive late to be admitted into middle sets, having been experienced academic success in their first language, promote placing pupils with EAL. Even if the language accessibility distances the students' understanding of a lesson, they are put in the same class. Cummins (1993:72) recommends similar placement of students when he cites 
Vigotsky's (1978) 'zone of proximal development for pitching instruction for second language learners'. Vygotsky (1978) and Cummins (1993) support that for immigrant bilingual learners, instruction should be within a context embedded and cognitively demanding'. On the part of students, they are to develop academic and intellectual abilities that of instruction given by the teachers which also must be intellectually challenging for the learners.

\title{
8. LEARNERS WITH TURKISH SPEAKING ORIGIN IN THE UK
}

Among the ethnic minority students as bilingual and EAL learners, maybe the most familiar ones in terms of background, culture and learning difficulties, will be the children of the Turkish-speaking community in the UK, as well as being one of the best criteria to compare the quality and the success of the English language teaching at schools. The Turkishspeaking bilingual and EAL learners, except the country they live in now, do not differ from the Turkish learners in Turkey in any other language aspect. They might even suffer from a lack of a proper first language competence. They are at the same age, both new to English, share the same difficulties in grammar and pronunciation, and so on.

Over ten percent of pupils in maintained primary and secondary schools in England are from ethnic minority backgrounds, and over seven percent of pupils do not have English as their first language (DfEE and OFSTED, 1997:109). Especially in Hackney and Haringey, Turkish became the second most common language after Bengali among the pupils whose home language is other than English, according to the reports of London Borough of Hackney and Haringey (OFSTED, 1997). Some of the schools organise parents' nights specifically for Turkish-speaking pupils' parents and the schools never behave as 'culturally blind' or 'assimilationist'. In fact, the contrary is true (Enneli, 2002:5, $6)$.

\section{PROBLEMS FACED BY TURKISH STUDENTS IN THE UK}

A conference held in 2001 by Turkish educators, who moved to England years ago for some reason and decided to settle down as teachers, teacher assistants, deputies or even heads of the schools they worked for, enlightened the audience on the problems faced by Turkish Students within the British Education System. The speaker, who is currently a British citizen, Dedezade, $\mathrm{K}$. is a Turkish Cypriot and takes into consideration the issues of the Turkish students and their families after long years of education. According to the conference notes, he lists the problems under seven main titles which are:

\author{
o Language \\ o Racism \\ o Cultural clash \\ o Lack of parental interest \\ o Social status \\ o Clashing views on morals/ethics and discipline (parents and student) \\ o Parents not knowing English
}

Under the title of 'language problem', it is stated that those students who have had schooling in Turkey, and are literate in Turkish, learn and become literate in English much faster. This is not the case for many of our students (Dedezade, 2001).

It is an undesirable fact that although the Turkish-origin students born in the UK can speak informal, daily English fluently in the streets among their friends in two or three years' time, most of them seriously lack the essential skills to prove themselves in the schools and exams (Enneli, 2002). Consequently, it may be concluded from the observations of Dedezade and research by Enneli that being born in the UK is not a big advantage to learn proper English if there is not a good education specifically arranged for those pupils, and most of the newly-arrived Turkish pupils in the mainstream schools of England succeed better than the ones born there and adapt to the National contents of the lessons after overcoming the language barrier by the help of EAL programs and its intensive and positive effect on them.

\section{CULTURAL INCORPORATION}

Numerous studies have been carried out regarding to underachievement of ethnic minority students. These investigations have been followed by the governments to implement series of educational reforms to change the direction of underachievement amongst the ethnic minority students (Swann Report, 1985; Plowden Report, 1967; Bullock Report, 
1975). These studies are aimed to carry out to provide 'equality of educational opportunity' for all of the ethnic minority communities.

Cummins (1996:136) discusses the reasons why such interventions caused unimportant changes of ethnic minority pupils' failure to 'leave a deep structure of relationships between educators and culturally diverse students, largely untouched'. This indirectly involved constant power relationship in the classroom (Kozol, 1991). It can be said that this was largely production of low expectations towards the minority students (Mehmet Ali, 2001; Blauner, 1969; Ogbu, 1992). These attitudes often result in a continuum of reactions ranging from learning of values, attitudes of dominant group to rejection of those values in the sense of ambivalence or insecurity about their identities. What Cummins (1996) believed was at both extremes it results pupils disinterest from schooling and mental termination from academic effort. Therefore, we can say that for underachieving minority students the scope to which their culture and language is included into the school programme constitutes a significant academic success. To support Instruction language in the school, bilingual programmes using oral and literacy skills in L1 can help in the development of pupils' success. Cummins and Mulcahy (1978), Clarkson (1992) and Issa (2005) argues that this process is also reversible where the use of L1 and L2 are promoted in the curriculum which interchangeably results in cognitive advantages.

The requirement and the demands of the academic and cognitive language learning proficiency may be altered by the students' simple communication skills which also may hide their incompetency in the classroom language. Cummins (1984a) described this distinction in terms of Basic Interpersonal Communication Skills and Cognitive Academic Proficiency Skills.

\section{AFTER-SCHOOL CLUBS AND SUPPLEMENTARY SCHOOLS}

In order to address the needs of students' better learning, parents, educators and schools are seeking alternative ways to help their children within the schools or outside the schools. In the recent years, After School Clubs (ASCs) and Supplementary Schools (SSs) have been increased to a good number to serve TS community students which are organized by schools, non governmental organizations (NGOs) and charities. These are not only a case for TSSs but also there are ASCs and SSs for other ethnic minority communities, too. To a great extent, public demand for the ASCs and SSs reached a considerable amount. According to Miller (2003) the main purposes of the ASCs and SSs are to improve students' academic proficiency learning, increase their participation and help their academic achievement to improve their knowledge. These ASCs and SSs are not only planned to meet the needs of underachieving students but also they are designed to increase the cultural and language (home language) awareness. Therefore, the attendants of SSs and ASCs are not only the underachieving students but also those who score good. A principal of SSs, in an informal interview, highlighted the following reasons for it:

- cultural awareness

- to achieve better in the school subjects

- religious considerations

- $\quad$ education in the mother tongue

- $\quad$ one to one teaching

- help their English for their academic performance

- $\quad$ sportive activities

At the mainstream schools, some of the TS students fail to show expected better results because of various reasons such as lack of motivation, difficulty faced due to lack of understanding, parents not knowing child's instruction language and some other reasons that destruct students' learning. ASCs and SSs may provide support to attain better results in this regard. According to the informal interview with the SS principal, the researches indicate that SSs play an important role in making underachievers score better and polishing the skills of already bright students. All the students take a lot of advantage from SSs. He also stated that the findings show that underachievers in the mainstream schools attend these schools to achieve better as compared to those who do not follow regularly or do not keep up at all.

It is known that parents' background determines life chances of children. In other words, a child's chances of succeeding in life are still largely determined by their parents' income and social standing. Even in the UK, "having a large population of ethnic minorities and trying to provide equal opportunities for every single person in the borders of the country, there is no a really efficient government or private sector alternative to the help the Turkish origin children from a variety of unstable and poor backgrounds whose families are mostly in Kebab Shop, Coffee shop, restaurant or offlicense business, and no one takes this critical issue into consideration by placing importance on as much as we do" says SS principal in our informal conversation. Although many charities offer respite breaks, many of them offer the long- 
term care and support by forming on-going relationships with the children and the parents they help, they also create a foundation of support from which children can learn, develop and grow.

\section{CONCLUSION}

The purpose of this study was to examine closely the impact of the practices of mainstream British secondary schools on the achievements of Turkish Speaking Students, using ethnographic analysis and looking especially at social questions arising from the linguistic and ethnical boundaries and issues related to immigration.

The absence of an in-depth study of the actual strategies and techniques developed by teachers was a problematic gap in the existing research and one I wanted to overcome.

Patterns emerge in the literature which identify psychological factors as a significant cause of low performance, directly resulting from cultural displacement or inter-culturality. Other causes of failure are due to forms of competition between different cultural modes, and to the social status that immigrants tend to assume. Nevertheless, other factors also seem to play an important role, such as those arising from issues of bilingualism, or more precisely from the frequent deficiency in the command of English beyond an informal level, a condition related to the family group - often decisively precluding the typical dynamics of 'The Circles of Inclusion'.

In addition to the evidence provided in the literature, evidence was found in my research of a noteworthy mutual lack of understanding between what constitutes the school and the socio-cultural background of the students. Nevertheless, we also found among educators a certain degree of awareness of this lack of understanding, and, moreover, of the necessity to make the programme appropriate to TSSs, and on the other hand of the potential richness of the multicultural situation. Additionally, we have seen at the level of the strategies and techniques put in practice by teachers an important tendency towards the recognition of the cultural features of the students. Thus it is possible that possibilities for improvement lay in the potential of the informal knowledge possessed by the teachers in conjunction with institutional responses to their need to better understand students' socio-cultural background.

\section{BIBLIOGRAPHY}

- Alkan F. \& Constantinides S. (1982) Cypriots in Haringey. Borough of Haringey, London.

- Berger, B. A. (1975), Attainment and Adjustment in Two Geographical Areas. The British Journal of Psychiatry .p, 520-533.

- Bhatti, F. M. (1981), Turkish Cypriots in Britain. Research Papers - Muslim in Europe, N. 11. Birmingham: Centre for the Study of Islam and Christian-Muslim Relations, p. 2.

- $\quad$ Blauner, R. (1969), Internal Colonialism and Ghetto Revolt. Social Problems, 16, pp. 393-408.

- Bonnett, A. (2000), Fitting into Categories or Falling Between Them? Rethinking ethnic classification. British Journal of Sociology of Education, Vol,21, Issue 4 December 2000 , pages 487 - 500.

- Bullock, A (1975), Bullock report. Report of the committee of inquiry appointed by the secretary of state for education and science under the chairmanship of Sir Alan Bullock.

- Clarkson, P.C.(1992), Language and Mathematics; A comparison of bilingual and monolingual students of mathematics. Educational studies in Mathematics 23, pp. 417-429.

- Clough, H.E. and Quarmby, J. 1978), A Public Library Service for Ethnic Minorities in Great Britain, London: CILT.

- Costantinides, P. (1977), 'The Greek Cypriots: Factors in the Maintenance of Ethnic Identity', in Watson, J.L. (ed.) Between Two Cultures, London: Basil Blackwell.

- Cummins, J. (1984a), Bilingualism and Special Education: Issues in Assessment and Pedagogy, Clevedon: Multilingual Matters.

- Cummins, J. (1996) Negotiating Identities: Education for Empowerment in a Diverse Society. California: Association for Bilingual Education. Cambridge: Cambridge University Press.

- Dedezade, K. (2001, June 25). Conference: The Problems Faced by Turkish Students within the British Education System. London: London Centre for Social Studies.

- DfES (Department for Education and Skills) (2006) The evidence on minority ethnic pupils aged 5-16. Ethnicity and Education. (0208-2006 DOM-EN) London: DfES, http://www.dfes.gov.uk/research/data/uploadfiles/02082006DOM-EN.pdf (Last accessed 12/08/2010)

- $\quad$ Dick, B. (2004). Action research literature: Themes and trends. Action Research, 2(4), 425-444.

- Enneli, P. (2002, 10 May). Listening to Turkish-Speaking Young People in the Secondary Schools. Paper Presented at Raising the Achievement of Turkish Speaking Pupils: Work in Progress Conference. London: Institute of Education, University of London. 
- Franson, M. D. (2001), Critical issues for language and content in mainstream classrooms: Introduction. Linguistics and Education 16 (2005) 143-150

- George, M. F. (1960). Models of American ethnic relations: A historical perspective. Cultural Divides. New York.

- Gibbons, P. (1991), Learning to Learn in a second Language. Heinemann

- Hackney Council, (1993), Planning for the Turkish/Kurdish Community in Hackney, Hackney Council, Environmental Services, London.

- Ignatiev, N. and Garvey, J. (1996). Race traitor. Rautledge Publishing, New York.

- Issa, T. (1987) Bilingual Education of Turkish Speaking Children in a Multicultural Environment, unpublished MSc thesis, London: Polytechnic of the South Bank.

- Issa, T. (2005) Talking Turkey: the language, culture and identity of Turkish speaking children in Britain. Stoke on Trent: Trentham, Books

- King, R. (1982), The Changing Distribution of Cypriots in London, in Etudes Migrations, Vol. 19, No. 65, pp. 93-120.

- Kozol, J. (1991), Savage Inequalities: Children in America's schools. New York: Crown Publishers.

- Kucukcan, T. (1999), Politics of Ethnicity, Identity and Religion: Turkish Muslims in Britain. Ashgate Publishing

- Kucukcan, T. (2001), Perspectives Of Multiculturalism-Western. Community, Identity and Institutionalisation of Islamic Education, Perspectives Of Multiculturalism - Western And Transitional Countries.pp1-310.

- Ladbury, S. (1979),Turkish Cypriots in London, Economy, Society and Culture. Unpublished Phd Thesis. London: SOAS, p. 309.

- Mehmet Ali, A. (2001). Turkish Speaking Communities \& Education No Delight. London : Fatal

- Miller, B. (2003) Afterschool Programs and Educational Success. The Nellie Mae Educational Foundation

- Mulcahy, D. L. (1978), Manipulation of gametophytic populations.

- Oakley, R. (1979), The Cypriot Migration to Britain, In V. S. Khan (Ed) Minority Families in Britain. London: Macmillan, pp. 13-34.

- OFSTED (Office for Standards in Education) (1997) LEA (Local Education Authority) Support for School Improvement: Inspection of Hackney Local Education Authority. London: OFSTED.

- Ogbu, J. U. (1992), 'Understanding Cultural Diversity and Learning', Educational Researcher, 21 (8), 5-14 \& 24.

- $\quad$ Paine, R. T. (1974), Disturbance, Patch Formation, and Community Structure. vol. 71 no. 7 2744-2747

- Plowden Report (1967), Children and Their Primary Schools, London: HMSO

- Rutter, J. (1994), Refugee Children in the Classroom. Trentham Books.

- Sonyel, S. R. (1988). The Silent Minority: Turkish Muslim Children in British Schools. Cambridge: The Islamic Academy.

- Swan, A.V. (1985), Relation between parents' and children's smoking behaviour and attitudes. Journal of Social Issues. p169-174.

- Vygotsky, L. S. (1978). Mind in society. Cambridge, MA: Harvard University Press. 